\title{
Manipulating spatial distance in virtual reality: Effects on treadmill walking performance in patients with intermittent claudication
}

Citation for published version (APA):

Cuperus, A. A., Keizer, A., Evers, A. W. M., van den Houten, M. M. L., Teijink, J. A. W., \& van der Ham, I. J. M. (2018). Manipulating spatial distance in virtual reality: Effects on treadmill walking performance in patients with intermittent claudication. Computers in Human Behavior, 79, 211-216.

https://doi.org/10.1016/j.chb.2017.10.037

Document status and date:

Published: 01/02/2018

DOI:

10.1016/j.chb.2017.10.037

Document Version:

Publisher's PDF, also known as Version of record

Document license:

Taverne

Please check the document version of this publication:

- A submitted manuscript is the version of the article upon submission and before peer-review. There can be important differences between the submitted version and the official published version of record.

People interested in the research are advised to contact the author for the final version of the publication, or visit the DOI to the publisher's website.

- The final author version and the galley proof are versions of the publication after peer review.

- The final published version features the final layout of the paper including the volume, issue and page numbers.

Link to publication

\footnotetext{
General rights rights.

- You may freely distribute the URL identifying the publication in the public portal. please follow below link for the End User Agreement:

www.umlib.nl/taverne-license

Take down policy

If you believe that this document breaches copyright please contact us at:

repository@maastrichtuniversity.nl

providing details and we will investigate your claim.
}

Copyright and moral rights for the publications made accessible in the public portal are retained by the authors and/or other copyright owners and it is a condition of accessing publications that users recognise and abide by the legal requirements associated with these

- Users may download and print one copy of any publication from the public portal for the purpose of private study or research.

- You may not further distribute the material or use it for any profit-making activity or commercial gain

If the publication is distributed under the terms of Article $25 \mathrm{fa}$ of the Dutch Copyright Act, indicated by the "Taverne" license above, 
Full length article

\title{
Manipulating spatial distance in virtual reality: Effects on treadmill walking performance in patients with intermittent claudication
}

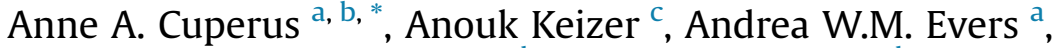

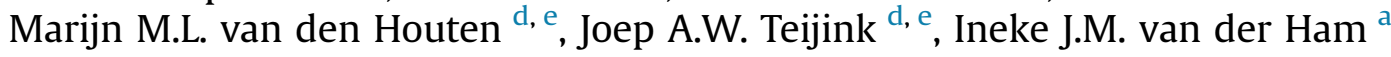 \\ ${ }^{a}$ Health, Medical and Neuropsychology, Leiden University, Wassenaarseweg 52, 2333 AK, Leiden, The Netherlands \\ b Triple, Keesomstraat 10E, 1821 BS, Alkmaar, The Netherlands \\ ${ }^{\mathrm{c}}$ Experimental Psychology, Utrecht University, Heidelberglaan 1, 3584 CS, Utrecht, The Netherlands \\ d Department of Vascular Surgery, Catharina Hospital, P.O. Box 1350, 5602 ZA, Eindhoven, The Netherlands \\ e CAPHRI Research School, Maastricht University, Universiteitssingel 40, 6229 ER, Maastricht, The Netherlands
}

\section{A R T I C L E I N F O}

\section{Article history:}

Received 4 July 2017

Received in revised form 13 October 2017

Accepted 22 October 2017

Available online 27 October 2017

\section{Keywords:}

Virtual reality

Pain distraction

Intermittent claudication

Distance manipulation

Treadmill

\begin{abstract}
A B S T R A C T
Research indicates that the manipulation of spatial distance between objects in a previously observed environment may go unnoticed when the categorical information of these objects, such as their order, matches that of memory for the environment. Using a repeated measures design, we investigated whether manipulations of spatial distance in virtual reality (VR) can influence treadmill exercise performance (i.e., walking distance) in patients with intermittent claudication; a cramping pain or discomfort in the legs, which occurs during exercise. Participants $(\mathrm{N}=19)$ carried out four treadmill exercise sessions; one without VR and three with a VR environment to move through while walking. They were instructed to walk until the pain forced them to stop. All VR sessions contained the same environment, but in the second and third session it was 'stretched' and 'compressed'. Walking distance was not influenced by the mere addition of VR. However, both VR manipulations led to greater walking distance than the VR baseline session and participants walked furthest when presented with the stretched environment. The results indicate that the manipulation of spatial distance in VR can be of clinical relevance; a finding that may be applied in the development of future medical applications.
\end{abstract}

(C) 2017 Elsevier Ltd. All rights reserved.

\section{Introduction}

Virtual reality (VR) is a computer technology that typically allows the user to look around in an artificial world, move through it and interact with it. VR is thereby capable of inducing a strong 'sense of presence', which is commonly described as the feeling of being physically situated within a spatial environment portrayed by a medium (see Wirth et al., 2007). It is often thought that an increased sense of presence magnifies 'user effects' (e.g., the extent to which users respond realistically to the mediated environment) and that this, in turn, increases the effectiveness of applications

\footnotetext{
* Corresponding author. Health, Medical and Neuropsychology, Leiden University, Wassenaarseweg 52, 2333 AK, Leiden, The Netherlands.

E-mail addresses: acuperus@gmail.com (A.A. Cuperus), a.keizer@uu.nl (A. Keizer), a.evers@fsw.leidenuniv.nl (A.W.M. Evers), marijn.vd.houten@ catharinaziekenhuis.nl (M.M.L. van den Houten), joep.teijink@ catharinaziekenhuis.nl (J.A.W. Teijink), c.j.m.van.der.ham@fsw.leidenuniv.nl (I.J.M. van der Ham).
}

(Cummings \& Bailenson, 2016). This is not only of great value for the entertainment industry, but has also proven to be useful in the field of healthcare, for clinicians and patients alike. For instance, VR exposure therapy has helped people overcome specific phobias, such as fear of height or spiders, since at least the mid-nineties (Rothbaum et al., 1995; for meta-analyses see e.g., Morina, Ijntema, Meyerbröker, \& Emmelkamp, 2015; Parsons \& Rizzo, 2008). Another popular example is the use of VR as a pain reduction technique in the treatment of acute pain (Garrett et al., 2014), such as pain experienced during wound care by patients with severe burn injuries (Hoffman, Patterson, Carrougher, \& Sharar, 2001; Hoffman et al., 2008).

Overall, VR in healthcare is still in its early days in terms of novel treatment paradigms. In case of VR exposure therapy, the added value over real-life ('in vivo') exposure seems to be that it allows exposure to all kinds of real-world situations (e.g., standing on top of a flat, or being surrounded by spiders) at a single location, thereby providing a cost- and time-efficient alternative. There are other advantages, such as that VR allows control over the artificial 
stimuli (i.e., the virtual environment can be adjusted or abandoned at any given moment), but the main benefits seem to be of practical nature. In case of VR as a pain reduction technique, being able to induce a sense of being situated within a VR environment serves a different purpose. Although the exact mechanisms remain unclear, VR is generally hypothesized to be capable of reducing pain by means of distraction (Garrett et al., 2014). Conscious attention is required to process pain signals and VR can provide an engaging environment which draws a lot of attentional resources, leaving less attention available to process these pain signals (Hoffman et al., 2001).

Although VR is used effectively in the aforementioned examples, its most valuable feature may be that it is not subject to the same limitations as the physical world; VR allows the user's environment to be manipulated in ways that are difficult or even impossible to realize otherwise. It is therefore relevant to establish which manipulations VR allows for, to test their user effects and to explore whether these manipulations can be of clinical relevance. Such knowledge may serve as guidelines for the development of future medical applications and the aim of our study was to contribute in this line of research. Cuperus and van der Ham (2016) previously investigated the effect of manipulating the spatial distance between objects in VR on memory. In this study, participants took shots at a target on a soccer field and were shown three different types of VR replays of their performance on this task; one accurate representation of actual performance and two manipulated representations in which the distance between the ball and the goalpost was adjusted. One manipulation made performance seem worse (miss distances multiplied by 1.5 ) and the other made performance seem better (miss distances multiplied by 0.5 ). Interestingly, however, all three were considered equally accurate representations of actual performance, indicating that the distance manipulations were not noticed. Moreover, the type of manipulation positively correlated with participants' feeling of competence with respect to the task.

The results of this soccer study can be explained in light of how people memorize spatial relations between objects and between objects and themselves. Kosslyn (1987) proposed a distinction between the representations of coordinate (metric) and categorical spatial relations (e.g., the side of an object in relation to another object). Typically, people are not very accurate in memorizing the precise metric properties of objects and their locations, especially after longer temporal delays. The same holds true for memory retrieval, which is a reconstructive process (Bartlett, 1932) that is susceptible to misleading, suggestive information (Loftus, 2005). The VR replays in the study by Cuperus and van der Ham matched participants' memory in terms of the categorical spatial relations that were of main importance to the task (i.e., the side of the goalpost along which the ball passed for each shot), which could well explain why the manipulations were not noticed.

In the present study, we investigated whether the manipulation of spatial distance in VR can also be of clinical relevance. We focused on a specific clinical population; patients with intermittent claudication (IC). IC is a cramping pain or discomfort in the legs, which occurs during exercise, such as walking, and is relieved with rest (Lane, Ellis, Watson, \& Leng, 2014). Most often it is a symptom of peripheral artery disease, in which the arteries that supply blood to the limbs are obstructed due to atherosclerosis. Current guidelines appoint supervised exercise therapy, consisting of treadmillor track walking to moderate claudication pain, as primary treatment for patients with IC. A meta-analysis shows that this generally decreases patients' functional impairment, which is usually quantified as the distance that patients can walk before pain forces them to stop (Lane et al., 2014). However, motivating patients for such a painful exercise program forms a barrier to widespread prescription of supervised exercise therapy for all patients diagnosed with IC (Fokkenrood et al., 2014).

First, we tested whether VR can serve as a pain reduction technique in patients with IC. Up till now, all studies about pain and VR focused solely on pain outside control of the patient (e.g., pain experienced during wound care). What is special about claudication pain is that it is produced 'actively' by walking. Based on previous analgesic effects of VR on pain (for a review see Garrett et al. 2014) we expected that an engaging VR environment would also distract patients with IC from the pain in their legs during treadmill exercise and that this would lead to greater exercise performance (i.e., greater walking distance), thereby possibly increasing therapy effectiveness. Next, we examined whether manipulating the spatial characteristics in the VR environment in two subsequent VR treadmill exercise sessions would influence exercise performance further, by 'stretching' and 'compressing' the environment in the direction of its walkway. When learning a route, people initially build up knowledge of landmarks. Metric properties such as distance or temporal duration are believed to be acquired gradually with experience (McNamara, Sluzenski, \& Rump, 2008), so in interpreting the environment in subsequent VR sessions we expected patients to rely mostly on the categorical information they acquired earlier. Because this information (i.e., landmarks and their order) matched that of the first VR session, we expected that the spatial manipulations would not be noticed (Cuperus \& van der Ham, 2016). The subsequent sessions also included a flag which marked the location of the previously reached walking distance $( \pm$ $10 \%$, depending on condition), thereby setting visual, attainable goals. We reasoned that patients would be motivated to pass or at least reach their prior record, leading to increased treadmill walking distance in the stretched VR condition and decreased walking distance in the compressed VR condition. Finally, aside from its effects on performance, we explored whether treadmill exercise with VR would be considered more enjoyable than exercise without VR.

\section{Material and methods}

\subsection{Participants}

To be eligible, participants had to be diagnosed with IC and follow supervised treadmill exercise therapy twice a week at one of three participating physiotherapy clinics. Exclusion criteria were motion sickness, balance problems, dementia and a history of heart disease or epilepsy. A total of 23 patients were recruited by their treating therapists. Data of three participants was excluded from analyses, as they did not finish all experimental sessions due to circumstances unrelated to IC or the experiment. Data of one participant was excluded because it contained a walking distance that was considered an outlier (outside the range of $M \pm 2.5 S D$ for the relevant measure and condition). The mean age of the remaining 19 participants ( 6 male, 13 female) was 72.6 years (range 49-92; $S D=11.6)$. Comorbidity consisted of chronic obstructive pulmonary disease $(\mathrm{N}=6)$, diabetes mellitus type $2(\mathrm{~N}=4)$, peripheral neuropathy $(N=2)$, hypertension $(N=2)$, rheumatoid arthritis $(\mathrm{N}=2)$, thyroid deficiency $(\mathrm{N}=1)$ and hypercholesterolemia $(\mathrm{N}=1)$.

\subsection{Ethical approval}

This study adhered to the Declaration of Helsinki (World Medical Association, 2013). The Medical Ethical Committee Noord-Holland considered the study not to fall under the Medical Research Involving Human Subjects Act (reg. no. M016-009), because participants were not subject to procedures and were 
not required to follow rules of behavior.

\subsection{Task and measures}

\subsubsection{Treadmill exercise task}

Participants carried out a treadmill exercise task under four different conditions. They were instructed to walk as far as possible and to report the moment they wished to stop because the pain forced them to (i.e., their maximum walking distance) verbally.

\subsubsection{Questionnaire}

After all exercise tasks were finished, participants were asked to rate how fun they considered the exercise sessions with VR and the one without, on two $100 \mathrm{~mm}$ paper visual analogue scales (VAS) that ranged from 0 (no fun at all) to 100 (extremely fun; for similar measures of fun see e.g., Hoffman et al., 2004; Wallot, Mitkidis, McGraw, \& Roepstorff, 2016). The questionnaire also contained an open question about what they believed was being tested, to check if they noticed the VR environment was manipulated in the second and third VR session.

\subsection{Conditions}

Other than during regular treadmill exercise, in the 'no VR' condition the treadmill's information display was covered for participants so that no information about walking time or distance was available to them. Also, the treating therapists did not go into conversation with participants during exercise, but remained silent and out of participants' vision. In addition to this, in the 'VR baseline' condition participants moved through the VR environment while walking on the treadmill. This environment consisted of a colorful forest with a walkway and contained several dynamic elements that were intended to distract from the pain during walking, such as animals crossing the path and the trees constantly changing color over time (see Fig. 1). Sound was found to enhance the analgesic effect of VR (Johnson \& Coxon, 2016), so sounds were included of animals and of the wind blowing through the trees. In two subsequent VR conditions a flag was added to the same environment at the location matching the walking distance reached in the prior VR session. Furthermore, the whole environment, including the newly added flag, was stretched and compressed in the direction of the walkway by $10 \%$ (in comparison to the baseline environment), thereby increasing ('VR increased') and decreasing
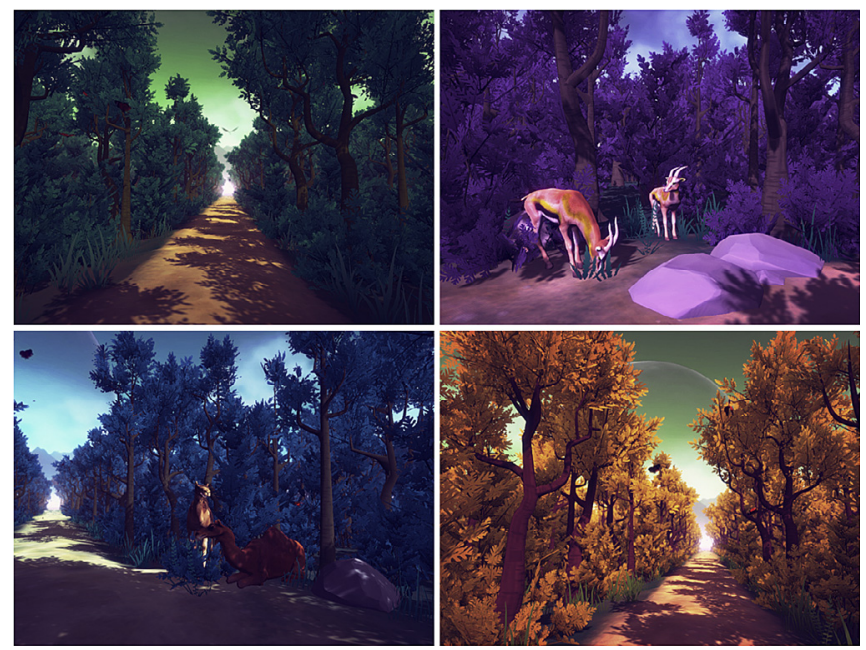

Fig. 1. Screenshots of the VR (baseline) environment that participants moved through while walking on the treadmill.
('VR decreased') the distance between all objects.

Because the VR baseline condition needed to be followed by the other VR conditions, we were limited in our ability to randomize the order of conditions. Participants who started their first session without VR were offered the VR baseline condition in the second session. For the ones who started with the VR baseline condition, the last exercise session contained no VR. Furthermore, for half of all participants VR baseline was followed by VR decreased and then VR increased and for the other half it was followed by VR increased and then VR decreased. This amounted to a total of four different orders of conditions to which participants were assigned based on order of entry:

1 No VR $\rightarrow$ VR baseline $\rightarrow$ VR decreased $\rightarrow$ VR increased

2 No VR $\rightarrow$ VR baseline $\rightarrow$ VR increased $\rightarrow$ VR decreased

3 VR baseline $\rightarrow$ VR decreased $\rightarrow$ VR increased $\rightarrow$ No VR

4 VR baseline $\rightarrow$ VR increased $\rightarrow$ VR decreased $\rightarrow$ No VR

\subsection{Procedure}

The experiment took place in the three clinics where participants normally carried out their treadmill exercise and consisted of four treadmill exercise sessions; one for each condition, separated from each other by periods of three days. To make sure that the same procedure was followed in each clinic, all measurements were carried out by the same experimenter. The treating therapists were always present as well, so they could intervene if deemed necessary (but this was never the case). To reduce environmental noise, no other people were allowed inside the exercise area and all doors and windows were closed. Furthermore, the temperature was always set to $21{ }^{\circ} \mathrm{C}$ and participants' sessions were all scheduled at the same time for each day.

Before the first exercise session, participants read the information sheet and signed the consent form. The information sheet stated that the goal of the experiment was to test the effects of moving through a VR environment on walking performance several times. Participants were verbally instructed about the experiment, after which they took a seat for $5 \mathrm{~min}$. This way they could recover from any possible fatigue caused by walking up the stairs towards the exercise area for instance. They then stepped onto the treadmill for the first exercise session. The ones who started with the VR baseline session also put on a VR headset through which the VR environment was visible during exercise. The treadmill was then started at participants' usual treadmill exercise speed. In the VR session, this speed was also manually entered in the settings of the application so that the visuals would match participants' walking speed. The distance value (measured in meters) matching the verbally reported moment participants wished to stop was read from the treadmill's information display, after which the treadmill was turned off. The following three sessions followed the same procedure and participants filled out the questionnaire after the last session. They were then informed about the actual goal of the experiment and were told in which order the different VR conditions were offered.

\subsection{Materials}

The VR application was developed in collaboration with Triple (Alkmaar, the Netherlands) and Gamedia (Alkmaar, the Netherlands). The VR headset we used was the first consumer edition of the Oculus Rift (Oculus VR; Menlo Park, California) and the PC we used to run the application on was equipped with an NVIDIA GeForce GTX 1070 graphics card (NVIDIA; Santa Clara, California). This allowed the application to run at a high frame rate 
(90 FPS). Life Fitness F3 (Life Fitness; Rosemont, Illinois) fixedspeed treadmills were used in all three clinics. The main statistical analyses were carried out using IBM SPSS Statistics 23 (IBM; Chicago, Illinois). We used G* Power 3.1.9.2 for Windows (Düsseldorf, Germany) to carry out the power analyses.

In VR, there is a perceptual distortion of the speed of optic flow. Whereas in normal walking the ratio of optic flow to speed of walking, known as visual gain, is $1: 1$, in VR the optic flow needs to be relatively faster for it to appear normal (Powell, 2011). Optimal perceived visual gain was reported to be as low as 1.3:1 (Durgin et al., 2005) and as high as 2:1 (Kassler, Feasel, Lewek, Brooks Jr, \& Whitton, 2010). Not only is it dependent on several setuprelated factors, such as the inclusion of near-space objects in VR (Nilsson, Serafin, \& Nordahl, 2014) or the geometric field of view size (Nilsson, Serafin, \& Nordahl, 2015), but there is also considerable variation between individuals in the perception of visual gain (Durgin et al., 2005). We set the visual gain to 1.3:1 in our experiment. Participants were told that this ratio could be adjusted if it felt unrealistic, but none of them reported this to be the case.

\subsection{Data analyses}

As participants differed from one another in their degree of functional impairment, we did not use absolute walking distances in the analyses. Instead, for each participant we divided the walking distance of each session by the total walking distance of all four sessions and multiplied these scores by 100 , allowing a comparison of relative differences in performance between participants. For the hypothesis that the addition of VR would lead to increased walking distance, these scores were then compared with a paired samples $t$ test (no VR vs. VR baseline). Second, we analyzed the answer to the open question of the questionnaire by separating and describing answers indicating that participants noticed any kind of difference between the VR environments from answers indicating that they noticed no difference at all. Next, a repeated measures ANOVA was carried out to test whether the manipulation of spatial distance influenced walking distance, with manipulation type (VR baseline vs. VR increased vs. VR decreased) as within-subjects factor. We also conducted a post-hoc power analysis based on the outcome of the repeated measures ANOVA to determine the power we achieved with the sample that we included in the study. This was followed by an a priori power analysis to indicate the necessary sample size for an adequate reproduction of the results. Finally, to test whether VR was considered more enjoyable, the VAS scores on subjective experience of fun (no VR vs. VR) were compared with a paired samples $t$-test.

\section{Results}

Fig. 2 shows the mean walking distance for each treadmill exercise condition. The paired samples $t$-test showed that the average walking distance in the first exercise session with VR did not significantly differ from the average distance in the session without $\mathrm{VR}, t(18)=0.67, p=0.51$. This suggests that the mere addition of VR did not influence exercise performance.

None of participants' answers to the open question of the questionnaire indicated that they noticed any kind of difference between the three VR environments. It therefore seems that the spatial manipulation of distance in the second and third VR session were not noticed.

The repeated measures ANOVA showed that walking distance was significantly influenced by type of manipulation, $F(2$, $36)=32.55, p<0.01, \eta_{\mathrm{p}}^{2}=0.64$. Post-hoc Bonferroni corrected ttests showed that the average distance in the baseline VR session was significantly smaller than the average distance in both the VR

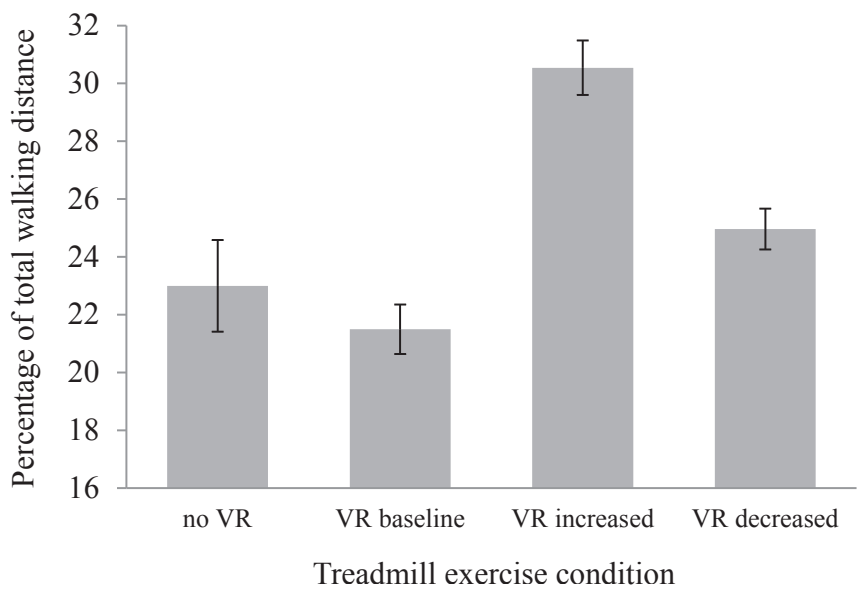

Fig. 2. Mean percentage of total walking distance for each treadmill exercise condition. The error bars represent standard errors.

increased condition, $p<0.01$, and VR decreased condition, $p<0.01$. Also, participants walked significantly further in the VR increased condition than in the VR decreased condition, $p<0.01$.

With an effect size $f$ of 1.33 , alpha set at 0.05 , correlation among repeated measures at 0.50 and nonsphericity correction at 1.00 , the post-hoc power analysis showed that the achieved power was 1.00. The a priori power analysis further indicated that in order to adequately reproduce these results, a study should include at least 8 subjects.

Finally, the second paired samples t-test indicated that participants rated the exercise session without VR $(M=49.84, S E=5.67)$ as significantly less fun than the sessions with VR $(M=76.89$, $S E=4.94), t(18)=4.42, p<0.01, d=1.02$.

\section{Discussion}

The most valuable feature of VR may be that it is not subject to the same limitations as the physical world; it allows the user's environment to be manipulated in ways that are difficult or even impossible to realize otherwise. The main aim of our study was to investigate whether the manipulation of spatial distance in VR can be of clinical relevance and this was tested in patients with IC. Based on what we know about the analgesic effects of VR on pain from other studies, we first tested whether VR can serve as a pain reduction technique in patients with IC during treadmill exercise, leading to increased exercise performance. Second, we examined whether manipulating the spatial characteristics in the VR environment in two subsequent VR treadmill exercise sessions would influence performance further.

VR is generally hypothesized to be capable of reducing pain by means of distraction (Garrett et al., 2014). We expected that an engaging VR environment would also distract patients with IC from the pain in their legs during treadmill exercise and that this would lead to increased treadmill exercise performance. However, we found that walking distance in the first exercise session with VR did not differ from the distance in the session without VR, which suggests that exercise performance was not influenced by the addition of VR. One explanation for this may be found in that claudication pain builds up gradually during exercise. Research suggests that pain competes with other attention-demanding stimuli for an overlapping set of limited cognitive resources (Buhle \& Wager, 2010; Moriarty, McGuire, \& Finn, 2011), which means that as pain increases, the effectiveness of distraction may decrease. Perhaps the distractive elements of the VR application we 
used were not intense enough to distract participants from the higher levels of pain towards the end of exercise. We therefore do not rule out the possibility that a more distracting VR environment, or an environment that becomes more intense as pain increases, can increase exercise performance in patients with IC and we believe this is worth further investigation.

In two subsequent VR conditions, the whole environment was stretched and compressed in the direction of the walkway. Because the categorical information (i.e., landmarks and their order) in these sessions matched that of the baseline VR session, we expected that these spatial manipulations would not be noticed (Cuperus \& van der Ham, 2016). The answers to the open question of the questionnaire indicated that this was indeed the case. The subsequent sessions also included a flag which marked the location of the walking distance reached in the prior VR session $( \pm 10 \%$, depending on condition), thereby setting visual, attainable goals. We reasoned that patients would be motivated to pass or at least reach their prior record, leading to increased walking distance in the stretched VR condition and decreased distance in the compressed VR condition. This was partially confirmed; the results showed that participants walked furthest when presented with the stretched environment, but also that they walked least in the VR baseline session, instead of in the session with the compressed environment. Although a possible criticism might be that the sample size of the present study was on the small side, our power analyses showed that an adequate reproduction of these effects requires only about half the amount of subjects we tested.

A probable explanation for the weaker performance in the baseline session seems to be that a lack of visual goals in this session resulted in lower motivation and, in turn, smaller walking distance. More important however is the observation that both the second and third VR session contained the same visual goal, while participants walked further with the stretched environment. This is interesting, because it seems that they did not notice the difference between the different conditions, which indicates that treadmill exercise can benefit from the increase of spatial distance in VR. However, the link between motivation, pain and walking distance comes into question here; did participants reach greater distances because they were motivated to surpass prior records and/or did they experience more pain post exercise? In contrast, if motivation was lower in the baseline condition, this may not only have resulted in smaller walking distance, but also in less pain. Measures of motivation and pain were not included in the study, but we do think that future studies should take these into account. Also, we suggest that future research should explore the boundaries of distance manipulations (i.e., to what extent do they go unnoticed and under which conditions), as well as their possible utility with respect to medical conditions other than IC.

\section{Conclusion}

Taken together, the results of our study indicate that the manipulation of spatial distance in VR can be of clinical relevance; a finding that may be applied in the development of future medical applications. Furthermore, treadmill exercise with VR was considered more enjoyable than exercise without VR, which in itself is an indication that therapy can benefit from this type of VR applications.

\section{Funding}

This work was supported by the Netherlands Organization for Scientific Research (NWO) [Veni grant 451-12-004]. NWO had no involvement in the study design, in the collection, analysis and interpretation of data, in the writing of the report and/or in the decision to submit the article for publication.

\section{Author contributions}

AC developed the study concept. AC, IH and AK contributed to the study design. Data was collected and analyzed by AC under the supervision of IH and AK. AC drafted the manuscript and $\mathrm{IH}, \mathrm{AK}, \mathrm{AE}$, $\mathrm{MH}$ and JT provided critical revisions. All authors approved the final version of the manuscript for submission. Conflicts of interest: none.

\section{Acknowledgements}

We are grateful to the physiotherapy clinics that participated in the study: Fysiotherapie Elisabeth (Alkmaar, The Netherlands), Fysiotherapeutisch Centrum Knieriem \& Van Bergen (Bennekom, The Netherlands) and Topfysiotherapie De Waterleeght (Kaatsheuvel, The Netherlands). We are also thankful to Robert Overweg and Maarten Laken for their assistance in the design of the application.

\section{References}

Bartlett, F. C. (1932). Remembering: An experimental and social study. Cambridge: Cambridge University.

Buhle, J., \& Wager, T. D. (2010). Performance-dependent inhibition of pain by an executive working memory task. Pain, 149(1), 19-26. https://doi.org/10.1016/ j.pain.2009.10.027.

Cummings, J. J., \& Bailenson, J. N. (2016). How immersive is enough? A metaanalysis of the effect of immersive technology on user presence. Media Psychology, 19(2), 272-309. https://doi.org/10.1080/15213269.2015.1015740.

Cuperus, A. A., \& van der Ham, I. J. M. (2016). Virtual reality replays of sports performance: Effects on memory, feeling of competence, and performance. Learning and Motivation, 56, 48-52. https://doi.org/10.1016/j.lmot.2016.09.005.

Durgin, F. H., Pelah, A., Fox, L. F., Lewis, J., Kane, R., \& Walley, K. A. (2005). Selfmotion perception during locomotor recalibration: More than meets the eye. Journal of Experimental Psychology: Human Perception and Performance, 31(3), 398-419. https://doi.org/10.1037/0096-1523.31.3.398.

Fokkenrood, H. J. P., Scheltinga, M. R. M., Koelemay, M. J. W., Breek, J. C., Hasaart, F., Vahl, A. C., et al. (2014). Significant savings with a stepped care model for treatment of patients with intermittent claudication. European Journal of Vascular and Endovascular Surgery, 48(4), 423-429. https://doi.org/10.1016/ j.ejvs.2014.04.020.

Garrett, B., Taverner, T., Masinde, W., Gromala, D., Shaw, C., \& Negraeff, M. (2014). A rapid evidence assessment of immersive virtual reality as an adjunct therapy in acute pain management in clinical practice. The Clinical Journal of Pain, 30(12), 1089-1098. https://doi.org/10.1097/AJP.0000000000000064.

Hoffman, H. G., Patterson, D. R., Carrougher, G. J., \& Sharar, S. R. (2001). Effectiveness of virtual reality-based pain control with multiple treatments. The Clinical Journal of Pain, 17(3), 229-235. https://doi.org/10.1097/00002508-20010900000007.

Hoffman, H. G., Patterson, D. R., Magula, J., Carrougher, G. J., Zeltzer, K., Dagadakis, S., et al. (2004). Water-friendly virtual reality pain control during wound care. Journal of Clinical Psychology, 60(2), 189-195. https://doi.org/10.1002/jclp.10244.

Hoffman, H. G., Patterson, D. R., Seibel, E., Soltani, M., Jewett-Leahy, L., \& Sharar, S. R. (2008). Virtual reality pain control during burn wound debridement in the hydrotank. The Clinical Journal of Pain, 24(4), 299-304. https://doi.org/10.1097/ AJP.0b013e318164d2cc.

Johnson, S., \& Coxon, M. (2016). Sound can enhance the analgesic effect of virtual reality. Royal Society Open Source, 3(3), 150567. https://doi.org/10.1098/ rsos.150567.

Kassler, L., Feasel, J., Lewek, M. D., Brooks, F. P., Jr., \& Whitton, M. C. (2010). Matching actual treadmill walking speed and visually perceived walking speed in a projection virtual environment. In D. Gutierrez, J. Kearney, M. Banks, \& K. Mania (Eds.), Proceedings of the 7th symposium on applied perception in graphics and visualization (p. 161). New York: ACM. https://doi.org/10.1145/1836248.1836283.

Kosslyn, S. M. (1987). Seeing and imagining in the cerebral hemispheres: A computational approach. Psychological Review, 94(2), 148-175. https://doi.org/ 10.1037/0033-295X.94.2.148.

Lane, R., Ellis, B., Watson, L., \& Leng, G. C. (2014). Exercise for intermittent claudication. Cochrane Database of Systematic Reviews, 2014(7), 1-122. https://doi.org/ 10.1002/14651858.CD000990.pub3.

Loftus, E. F. (2005). Planting misinformation in the human mind: A 30-year investigation of the malleability of memory. Learning \& Memory, 12(4), 361-366. https://doi.org/10.1101/lm.94705.

McNamara, T. P., Sluzenski, J., \& Rump, B. (2008). Human spatial memory and navigation. In H. L. Roediger (Ed.), Cognitive psychology of memory. Vol. 2 of Learning and memory: A comprehensive reference (pp. 157-178). Oxford: 
Elsevier. https://doi.org/10.1016/B978-012370509-9.00176-5.

Moriarty, O., McGuire, B. E., \& Finn, D. P. (2011). The effect of pain on cognitive function: A review of clinical andpreclinical research. Progress in Neurobiology, 93(3), 385-404. https://doi.org/10.1016/j.pneurobio.2011.01.002.

Morina, N., Ijntema, H., Meyerbröker, K., \& Emmelkamp, P. M. (2015). Can virtual reality exposure therapy gains be generalized to real-life? A meta-analysis of studies applying behavioral assessments. Behaviour Research and Therapy, 74, 18-24. https://doi.org/10.1016/j.brat.2015.08.010.

Nilsson, N. C., Serafin, S., \& Nordahl, R. (2014). Establishing the range of perceptually natural visual walking speeds for virtual walking-in-place locomotion. IEEE Transactions on Visualization and Computer Graphics, 20(4), 569-578. https:// doi.org/10.1109/TVCG.2014.21.

Nilsson, N. C., Serafin, S., \& Nordahl, R. (2015). The effect of visual display properties and gain presentation mode on the perceived naturalness of virtual walking speeds. In T. Höllerer, V. Interrante, A. Lecuyer, \& J. E. Swan, II (Eds.), Proceedings of the 22nd IEEE virtual reality conference (pp. 81-88). New York: Curran Associates, Inc. https://doi.org/10.1109/VR.2015.7223328.

Parsons, T. D., \& Rizzo, A. A. (2008). Affective outcomes of virtual reality exposure therapy for anxiety and specific phobias: A meta-analysis. Journal of Behavior Therapy and Experimental Psychiatry, 39(3), 250-261. https://doi.org/10.1016 j.jbtep.2007.07.007.
Powell, W. (2011). Virtually walking: Factors influencing walking and perception of walking in treadmill-mediated virtual reality to support rehabilitation (Doctora dissertation). Retrieved from https://researchportal.port.ac.uk/portal/files/ 6034084/Powell_W_PhD_thesis_for_binding.pdf.

Rothbaum, B. O., Hodges, L. F., Kooper, R., Opdyke, D., Williford, J. S., \& North, M. (1995). Virtual reality graded exposure in the treatment of acrophobia: A case report. Behavior Therapy, 26(3), 547-554. https://doi.org/10.1016/S00057894(05)80100-5.

Wallot, S., Mitkidis, P., McGraw, J. J., \& Roepstorff, A. (2016). Beyond synchrony: Join action in a complex production task reveals beneficial effects of decreased interpersonal synchrony. PLOS ONE, 11(12), e0168306. https://doi.org/10.1371/ journal.pone.0168306.

Wirth, W., Hartmann, T., Böcking, S., Vorderer, P., Klimmt, C., Schramm, H., \& Biocca, F. (2007). A process model of the formation of spatial presence experiences. Media Psychology, 9(3), 493-525. https://doi.org/10.1080| 15213260701283079.

World Medical Association. (2013). WMA Declaration of Helsinki: Ethical principles for medical research involving human subjects. Retrieved from: https://www. wma.net/policies-post/wma-declaration-of-helsinki-ethical-principles-formedical-research-involving-human-subjects/. 